\title{
Analysis of global research output on diabetes depression and suicide
} CrossMark

\author{
Waleed M. Sweileh*
}

\begin{abstract}
Background: Diabetic patients, during the course of the disease, are most likely to experience depressive symptoms that might ultimately lead to suicidal ideation or suicide. The size of literature in diabetes depression/suicide is a good indicator of national and international efforts to address psychological co-morbidities associated with diabetes mellitus (DM). Therefore, the objective of this study was to give a comprehensive analysis, both quantitative and qualitative, of scientific literature in diabetes depression/suicide.
\end{abstract}

Methods: SciVerse Scopus was used to retrieve relevant literature up to 2016.

Results: In total, 1664 journal documents were retrieved with an average of 26.9 citations per article and an $h$-index of 98. Publications started in 1949 but showed a steep and noticeable increase after 2001. Retrieved articles were published in 641 different journals with Diabetes Care journal being the top productive one with a total of 130 (7.8\%) articles. Researchers from 83 different countries participated in retrieved publications. Researchers from the United States of America participated in publishing 685 articles. There was a strong and positive correlation between research output and Gross Domestic Product $(r=0.083 ; p<0.001)$ but not with prevalence or mortality caused by DM. Researchers from 4870 different institutions/organizations participated in publishing retrieved articles. Publications from the University of Washington, Seattle, USA had the highest $h$-index (38), while "VA medical centers" had the highest number of publications $(75 ; 4.5 \%)$. In total, 5715 authors appeared in retrieved articles giving an average of 3.4 authors per article. Top cited articles focused on prevalence, impact of depression on glycemic control, and potential risk of diabetic complications. The total number of publications in depression/suicide in diabetic patients was lesser than that in cardiac (1938) or in cancer (1828) patients. However, publications in diabetes depression/suicide exceeded those in cardiac and cancer in the last 2 years of the study period.

Conclusion: The current study showed a noticeable growth of publications indicative of the importance of this topic. Research focusing on the psychiatric component of diabetes mellitus needs to be strengthened and encouraged. At the practical level, screening for depression/suicide among patients attending primary healthcare clinics is needed to optimize health and quality of life of diabetic patients.

Keywords: Diabetes mellitus, Depression, Suicide, Research output, Bibliometric analysis

\section{Background}

Diabetes mellitus (DM) is a chronic metabolic disease that requires careful changes in life style that can be demanding and difficult to implement by some diabetic patients [1]. According to World Health Organization's (WHO) recent report, the number of people diagnosed

*Correspondence: waleedsweileh@yahoo.com Department of Physiology and Pharmacology/Toxicology, College of Medicine and Health Sciences, Nablus, Palestine with diabetes mellitus (DM) has risen from 108 million in 1980 to 422 million in 2014 [2]. In 2012, an estimated 1.5 million deaths were directly caused by diabetes and another 2.2 million deaths were attributable to high blood glucose [2]. Diabetes mellitus is considered as a national and global health burden. It is estimated that at least $10 \%$ of healthcare expenditures in many countries is invested in preventing and combating DM complications [3]. Diabetes mellitus is not only a health and economic 
burden but also a social and psychological challenge that could ultimately lead to chronic depression.

Depression is a common mental disorder and according to the WHO, more than 300 million people worldwide had depression. Depression is a serious illness and if not properly addressed, it can affect the normal function of affected people and might sometimes lead to suicide [4]. Globally, there is an increased trend of suicide [5]. According to the $\mathrm{WHO}$, close to 800,000 deaths occur annually due to suicide and the majority (78\%) of these cases occur in low- and middle-income countries (LMIC) [6]. Psychiatric disorders are known to impair the control of chronic diseases such as DM and behavioral interventions in such conditions might have more pronounced effects than medications [7].

Diabetic patients, and during the course of the disease, are most likely to experience depressive symptoms that might ultimately lead to suicidal ideation or suicide. Published studies showed that individuals with diabetes have an increased incidence of major depression when compared to the general population [8-10]. The high prevalence of depression among diabetic patients had led to the term "diapression" [11]. Vascular changes due to DM could be the biological basis for the development of depression among diabetic patients [12]. The relationship between diabetes and depression could be bidirectional with one disease leading to the increased risk of having the other disease [13]. Regardless of the directionality of the disease, the presence of depression in diabetes mellitus could worsen self-care, poor medication adherence, increased healthcare cost, poor glycemic control, potential risk of diabetic micro- and macro-vascular complications, and poor QOL [14-16]. The presence of depression in diabetic patients could lead to suicide ideation and suicide attempts. Studies have shown that diabetic patients, particularly type $1 \mathrm{DM}$, have higher risk of suicide ideation and suicidal attempts than non-diabetic patients [17, 18].

In light of increasing incidence of diabetes mellitus and in light of geographical and social differences in healthcare services and health literacy in diabetes, the need to assess the growth of research on diabetes depression/suicide becomes very important. Quantitative and qualitative analysis of publications in a particular area is usually called bibliometrics or scientometrics in which statistical methods are applied on a set of retrieved publications [19]. Bibliometric analysis is a growing field of information science which had been applied to various scientific disciplines [20-24]. Bibliometric analysis is a key element in establishing baseline data for future comparison in any scientific subject. Bibliometric analysis in diabetes depression/suicide could help to establish strategies for improving the volume and quality of research in this field and the results could help to identify research gaps that future studies could focus on. The size of literature and research productivity in diabetes depression/suicide are good indicators of national and international efforts to decrease the health and economic burden of DM and the national and international efforts to address psychological co-morbidities associated with diabetes that could affect the QOL and glycemic control in diabetic patients.

To date, no studies have been published to summarize global research efforts, research trends, and geographical distribution of research output in diabetes depression/ suicide, despite that several bibliometric analyses in diabetes research activity had been published [21, 25-28]. Therefore, the objective of this study was to give a comprehensive analysis, both quantitative and qualitative, of scientific literature in diabetes depression/suicide.

\section{Methods}

\section{Bibliographic database}

For the purpose of this study, only peer-reviewed articles published in scientific journals indexed in SciVerse Scopus were retrieved. Gray literature such as governmental and non-governmental reports, brochures, dissertations, theses, and newsletters were not included because some of the gray literature especially thesis and dissertation might have been published as research articles in peerreviewed journals and therefore, they will create falsepositive results due to overlap. The choice of Scopus database was based on the understanding of the author that it is larger than Web of Science and includes 100\% of Medline [29]. Furthermore, Scopus has many analytic functions that facilitate bibliometric investigations of retrieved literature and therefore, it had been used in many previously published articles in the medical field.

\section{Research strategy and keywords}

To achieve the goal of the study, a set of related keywords pertaining or indicative of diabetes along with keywords related to depression or suicide were used. Keywords used in the search strategy were obtained from available systematic reviews [30-35]. The search strategy and keywords used along with the number of documents retrieved in each step are shown in Additional file 1: Appendix S1. To avoid any misinterpretation, we excluded publications in gestational diabetes mellitus and in experimental animals. The search strategy was based on searching for specific keywords in title of articles and not in abstract or author keywords. Actually, search for keywords in abstract and/or keywords yielded too many false-positive results that could negatively affect the validity of the study. 


\section{Validity check}

The validity of research strategy was checked by manual review of top 20 cited articles to guarantee the absence of false-positive results. Furthermore, visualized author keywords were used to check for any irrelevant terms or false-positive results. For example, it was noticed that some keywords such as neuropathic pain, diabetes insipidus were present in retrieved articles and therefore, such keywords were excluded. Finally, research productivity of top active authors was retrieved manually and compared with those obtained using the current search strategy. The correlation between the manually obtained results and those obtained by search strategy was high with an interclass correlation of $96.8 \%$ indicative of high validity of the results and very low percentage of false negative.

\section{Bibliometric indicators}

Retrieved documents were refined, analyzed, and mapped to show research contribution and research trends. The time span of the study was set from 1997 to 2016. The Hirsch index ( $h$-index) was used to assess the quality of published literature, while impact factor (IF) obtained from Journal Citation Report (2016) was used to assess the strength of publishing journals. Analysis of growth of publications with time was presented graphically using Statistical Package for Social Sciences (SPSS 21). For mapping keywords as well as international research collaboration, VOSviewer software was used [36]. In VOSviewer, the extent of collaboration is assessed by the thickness of a line connecting any two items such as countries or authors. For research productivity, the larger circle size or font size presenting a country or author, the greater the research productivity or citations of the listed author or country [36]. For geographical distribution of publications, ArcMap 10.1 software was used. Active institutions/organizations as well as most preferred journals for publishing articles in DSM were presented as top ten ones.

\section{Results}

The total number of retrieved articles was 1664 . Research articles constituted the majority (1311; 78.8\%) of retrieved documents followed by review articles (160; 9.6\%) (Table 1). The main language in retrieved articles was English (1497; 90.0\%) followed by German $(67 ; 4.0 \%)$ and Spanish $(30 ; 1.8 \%)$. Retrieved documents had an $h$-index of 98 and the highest number of citations recorded was 2060 for a meta-analysis study published in 2001 about the prevalence of depression among diabetic patients [37]. Retrieved documents received a total number of citations of 44,775 , an average of 26.9 citations per article. The vast majority of retrieved articles was about diabetes depression, while
Table 1 Types of retrieved documents

\begin{tabular}{lcc}
\hline Document type & Frequency & \% $(\boldsymbol{N}=\mathbf{1 6 6 4})$ \\
\hline Article & 1311 & 78.8 \\
Review & 160 & 9.6 \\
Letter & 63 & 3.8 \\
Note & 57 & 3.4 \\
Conference paper & 22 & 1.3 \\
Editorial & 19 & 1.1 \\
Short Survey & 18 & 1.1 \\
Article in Press & 14 & 0.8 \\
\hline
\end{tabular}

\section{Table 2 Subject areas of retrieved documents}

\begin{tabular}{lll}
\hline Document type & Frequency & \% $(\mathbf{N = 1 6 6 4})^{\mathbf{a}}$ \\
\hline Medicine (General and Internal) & 765 & 46.0 \\
Biochemistry, Genetics and immunology, & 311 & 18.7 \\
$\quad$ Biology, and Molecular Biology & & \\
Psychology & 227 & 13.6 \\
Nursing & 220 & 13.2 \\
Neuroscience & 80 & 4.8 \\
Social Sciences and Humanities & 92 & 5.5 \\
Pharmacology, Toxicology and Pharma- & 47 & 2.8 \\
ceutics & & \\
Health Professions & 41 & 2.5 \\
Multidisciplinary and Miscellaneous & 17 & 1.0 \\
\hline
\end{tabular}

a Total percentage exceeds $100 \%$ due to overlap in certain subject areas

$46(2.8 \%)$ articles were about diabetes suicide and suicidal ideation.

Of retrieved articles, $765(46 \%)$ were in the subject area of "Medicine", 311 (18.7\%) were in the subject area of "Biochemistry, genetics, immunology, and molecular biology", while 227 (13.6\%) were in the subject area of "psychology". Various subject areas of retrieved articles are shown in Table 2.

Growth of publications in diabetes depression/suicide started in 1949 with an article published in The New England Journal of Medicine about the effects of a large dose of insulin taken for suicidal attempt [38]. The number of publications in diabetes depression/suicide started in 1949, but remained very low until 2001. After 2001, the number of publications showed a steep and noticeable increase. Figure 1 shows the annual growth of publications in diabetes depression/suicide. Approximately, 92\% of retrieved articles were published during the period from 2001 to 2016 . The remaining $8 \%$ were published from 1949 to 2001. The highest number of publications recorded was 200 publications obtained in 2015.

Growth of publications was compared with that in other chronic diseases, particularly cancer and cardiac 
diseases. The total number of publications in diabetes depression/suicide (1664) was lesser than that in cardiac diseases depression/suicide (1938) and lesser than that in cancer depression/suicide (1828). However, the growth of publications in the three diseases showed that the ones in diabetes depression/suicide exceeded the other two in the last 2 years of the study period. Figure 2 showed the growth of publications in the three diseases with focus on the past three decades to facilitate comparison of growth of publications.

Retrieved articles were published in 641 different journals. Names of journals that published at least 10 documents are shown in Table 3 along with their most recent IF. The active list included a total of 18 journals with Diabetes Care being the top productive one with a total of $130(7.8 \%)$ articles. More than half $(10 ; 55.6 \%)$ of top active journals were in the field of diabetes and six were in the field of psychiatry/psychology $(6 ; 33.3 \%)$, one (Plos One) was multidisciplinary, and one was in internal medicine. Seventeen journals in the active list had an official IF and two had an IF above five.

Researchers from 83 different countries participated in publishing retrieved articles. Countries with a minimum productivity of 10 documents are listed in Table 4 along with the reported prevalence of DM in each country. No significant correlation existed between prevalence of DM and research productivity in diabetes depression/suicide. The most productive country was the United States of America (USA) with a total productivity of 685 documents followed by the United Kingdom (UK) with a total productivity of 125 documents. No significant correlation was found between research output and prevalence of DM or mortality caused by DM per 100,000 population. However, there was a strong and positive correlation between research output and GDP $(r=0.083 ; p<0.001)$. Despite that there was no significant correlation between research output and mortality rate caused by DM, there was a general trend of increased mortality caused by DM with low research output. This trend was obvious in countries such as Oman, Bahrain, Jordan, Morocco, South Africa, and Mexico (data not shown). Geographical distribution of publications showed that Africa, East Europe, and South America had poor research output in the field of diabetes depression/suicide. Figure 3 is a world map for geographical distribution of publications.

Researchers from 4870 different institutions/organizations participated in publishing retrieved articles. Institutions/organizations with a minimum productivity of 10

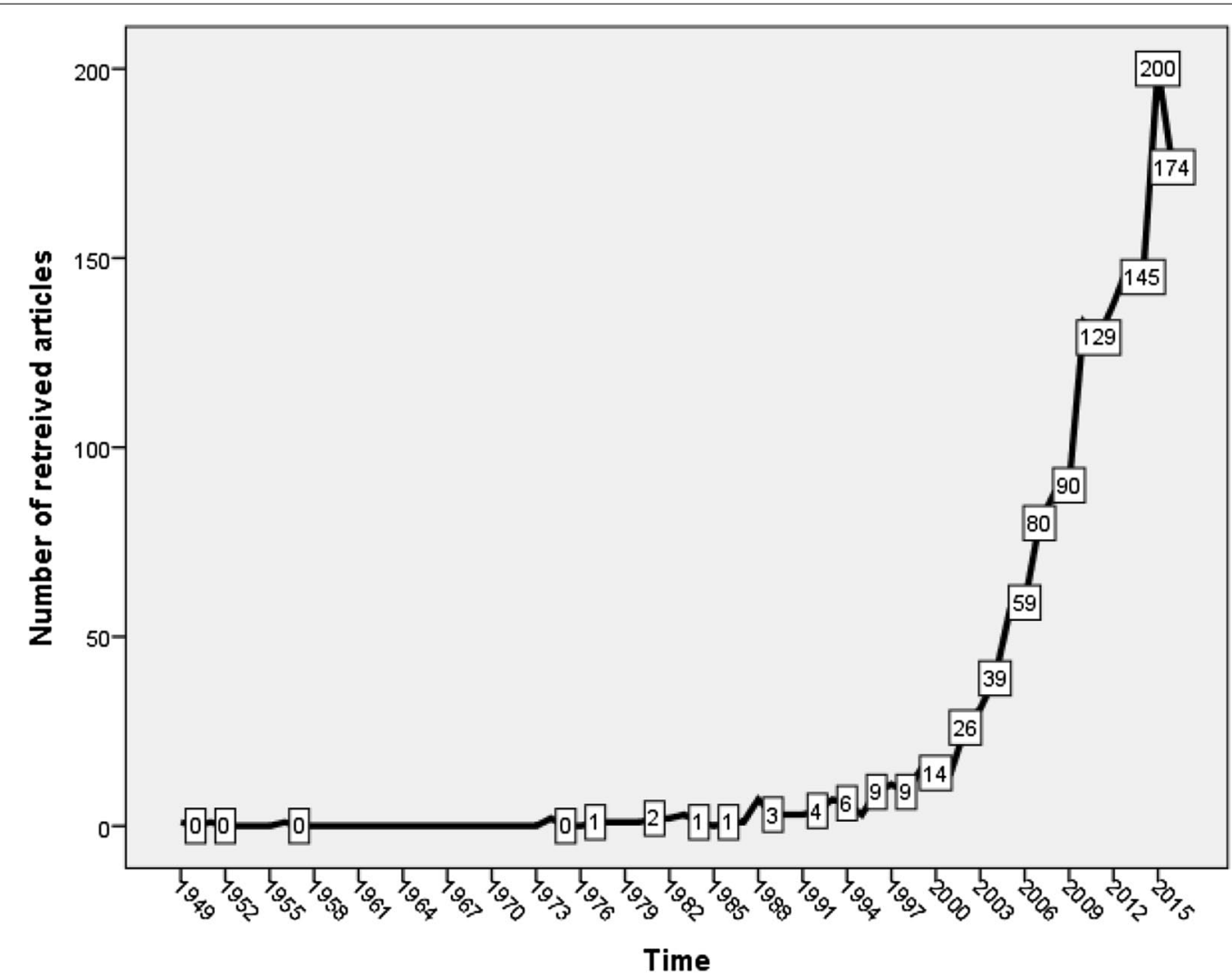

Fig. 1 Growth of publications in diabetes depression/suicide 


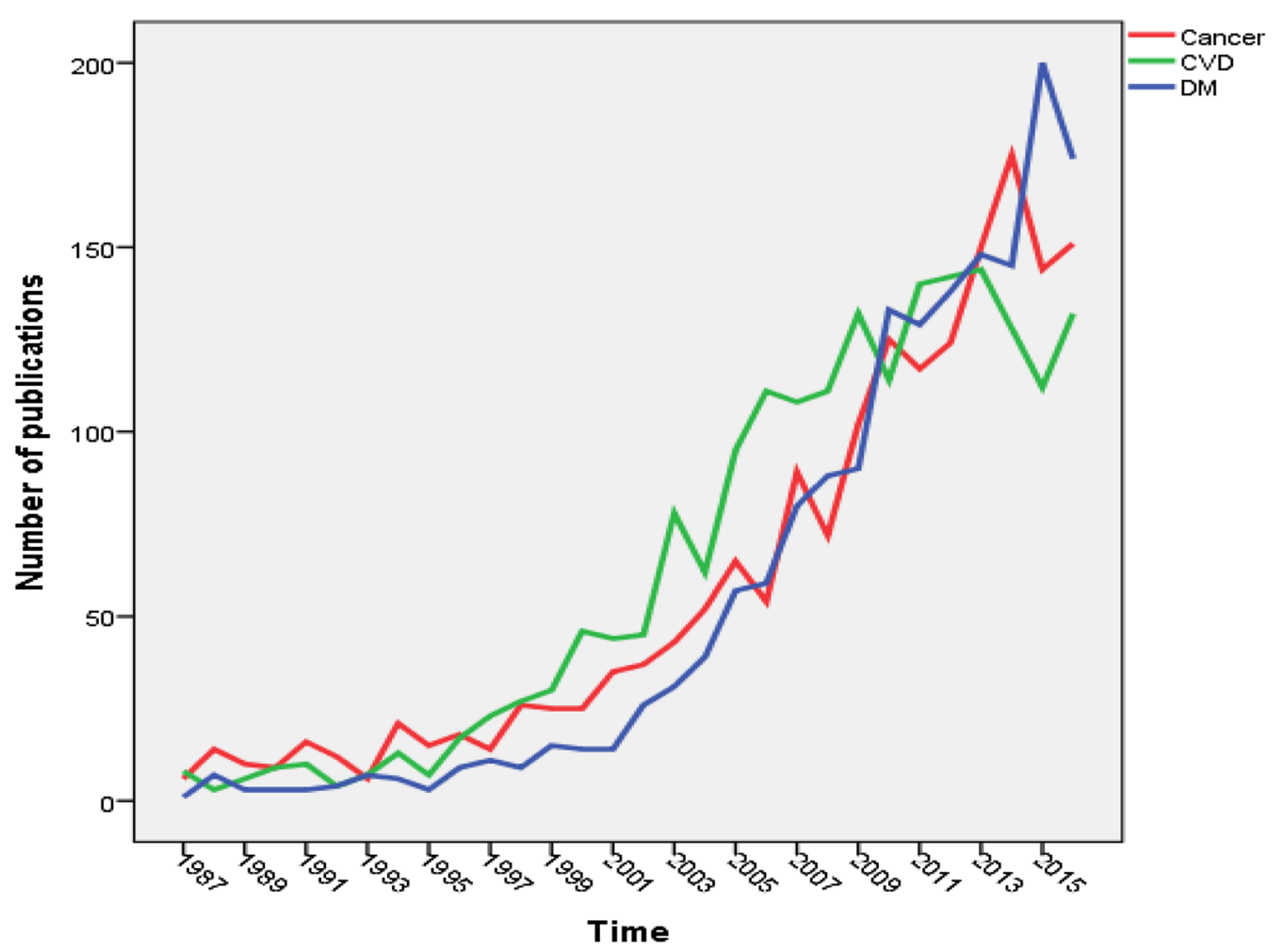

Fig. 2 Comparison of growth of publications in diabetes depression/suicide with that in cardiac diseases and in cancer (1986-2016). DM, diabetes mellitus; CVD, cardiovascular diseases

Table 3 List of journals with a minimum of 10 publications in diabetes depression/suicide

\begin{tabular}{lllll}
\hline Journal & Frequency & $\%(\mathbf{N}=\mathbf{1 6 6 4})$ & IF & Publisher \\
\hline Diabetes Care & 130 & 7.8 & 11.9 & ADA \\
Diabetic Medicine & 69 & 4.1 & 3.054 & Wiley \\
Diabetes Research and Clinical Practice & 39 & 2.3 & 3.693 & Elsevier \\
General Hospital Psychiatry & 29 & 1.7 & 2.279 & Elsevier \\
Journal of Affective Disorders & 28 & 1.7 & 3.432 & Elsevier \\
Journal of Psychosomatic Research & 26 & 1.6 & 2.809 & Elsevier \\
Psychosomatic Medicine & 25 & 1.5 & 3.863 & LWW \\
Diabetologia & 24 & 1.4 & 6.080 & Springer Berlin Heidelberg \\
Diabetologe & 23 & 1.4 & 0.072 & Springer Medizin \\
Plos One & 22 & 1.3 & 2.806 & Public Library of Science \\
Journal of Diabetes and Its Complications & 21 & 1.3 & 2.734 & Elsevier \\
Diabetes Educator & 17 & 1.0 & 1.811 & Sage \\
Psychosomatics & 17 & 1.0 & 2.436 & Elsevier \\
BMC Psychiatry & 16 & 1.0 & 3.701 & BioMed Central \\
Journal of General Internal Medicine & 13 & 0.8 & N/A & Springer US \\
Journal of The Japan Diabetes Society & 11 & 0.7 & 3.387 & Japan Diabetes Society \\
Current Diabetes Reports & 10 & 0.6 & N/A & Current Medicine Group \\
Diabetes Spectrum & 10 & 0.6 & & ADA \\
\hline
\end{tabular}

IF, impact factor; ADA, American Diabetes Association 
Table 4 List of countries with minimum participation of 10 articles in diabetes depression/suicide based on country affiliation of authors

\begin{tabular}{|c|c|c|c|c|c|}
\hline Country & Frequency & $\%(N=1664)$ & $\begin{array}{l}\text { Prevalence of DM } \\
\text { [93] }\end{array}$ & $\begin{array}{l}\text { Mortality per } 100,000 \text { population } \\
\text { caused by DM }[94]\end{array}$ & GDP (trillions) \\
\hline United States & 674 & 40.5 & $9.1 \%$ & 14.78 & 18.04 \\
\hline United Kingdom & 125 & 7.5 & $7.7 \%$ & 4.91 & 2.86 \\
\hline Germany & 121 & 7.3 & $7.4 \%$ & 11.43 & 3.36 \\
\hline Netherlands & 100 & 6.0 & $6.1 \%$ & 8.99 & 0.75 \\
\hline Australia & 77 & 4.6 & $7.3 \%$ & 11.05 & 1.2 \\
\hline Canada & 71 & 4.3 & $7.2 \%$ & 11.01 & 1.55 \\
\hline China & 57 & 3.4 & $9.4 \%$ & 14.8 & 11.06 \\
\hline India & 41 & 2.5 & $7.8 \%$ & 25.4 & 2.1 \\
\hline Japan & 37 & 2.2 & $10.1 \%$ & 4.37 & 4.38 \\
\hline Brazil & 35 & 2.1 & $8.1 \%$ & 39.74 & 1.8 \\
\hline Italy & 31 & 1.9 & $8.5 \%$ & 13.13 & 1.82 \\
\hline Poland & 31 & 1.9 & $9.5 \%$ & 10.07 & 0.477 \\
\hline Iran & 25 & 1.5 & $10.3 \%$ & 16.34 & 0.425 \\
\hline Mexico & 23 & 1.4 & $10.4 \%$ & 89.56 & 1.14 \\
\hline Turkey & 23 & 1.4 & $13.2 \%$ & 12.61 & 0.717 \\
\hline France & 21 & 1.3 & $8.0 \%$ & 8.78 & 2.42 \\
\hline Taiwan & 21 & 1.3 & - & - & 1.177 \\
\hline Norway & 19 & 1.1 & $6.6 \%$ & 8.64 & 0.387 \\
\hline Spain & 19 & 1.1 & $9.4 \%$ & 9.86 & 1.19 \\
\hline Finland & 17 & 1.0 & $7.7 \%$ & 4.66 & 0.232 \\
\hline South Korea & 15 & 0.9 & $9.5 \%$ & 16.01 & 1.378 \\
\hline Sweden & 14 & 0.8 & $6.9 \%$ & 9.68 & 0.496 \\
\hline Austria & 13 & 0.8 & $6.0 \%$ & 15.84 & 0.377 \\
\hline Switzerland & 13 & 0.8 & $5.6 \%$ & 7.67 & 0.671 \\
\hline Saudi Arabia & 12 & 0.7 & $14.4 \%$ & 35.61 & 0.646 \\
\hline Croatia & 11 & 0.7 & $9.9 \%$ & 14.04 & 0.049 \\
\hline Hong Kong & 11 & 0.7 & - & - & 0.309 \\
\hline Nigeria & 11 & 0.7 & $4.3 \%$ & 42.95 & 0.877 \\
\hline Belgium & 10 & 0.6 & $6.4 \%$ & 8.03 & 0.455 \\
\hline Pakistan & 10 & 0.6 & $9.8 \%$ & 39.65 & 0.271 \\
\hline
\end{tabular}

documents were shown in Table 5. The active top 10 list included seven institutions in the USA, two in Netherlands and one in Canada. Publications from the University of Washington, Seattle, USA had the highest $h$-index (38) while "VA medical centers" had the highest number of publications $(75 ; 4.5 \%)$.

In total, 5715 authors participated in publishing the retrieved documents giving an average of 3.4 authors per article. Authors with a minimum productivity of $10 \mathrm{doc}-$ uments and belong to a network of authors are visualized in Fig. 4. Visualization map of active authors included 36 authors grouped into six clusters. The largest cluster (red cluster) included 14 authors forming a network of collaboration. The size of the circle in the map reflects the size of the productivity, while the lines connecting the circles reflect the extent of author collaboration. Authors with the highest productivity include Katon W.J., Pouwer F., and Lustman P.J.

Top 20 cited articles are listed in Table 6. Top cited articles discussed issues related to epidemiology, impact of depression on glycemic control, diabetic complications/mortality, medication adherence, and quality of life. Four articles in top 20 cited articles discussed depression as a risk factor for diabetes and the bidirectional relationship between diabetes and depression. Analysis of author keywords using VOSviewer mapping showed that the following author keywords were most frequently encountered: "quality of life", epidemiology, prevalence, complications, screening, "primary care", adherence, self-management, mortality, 


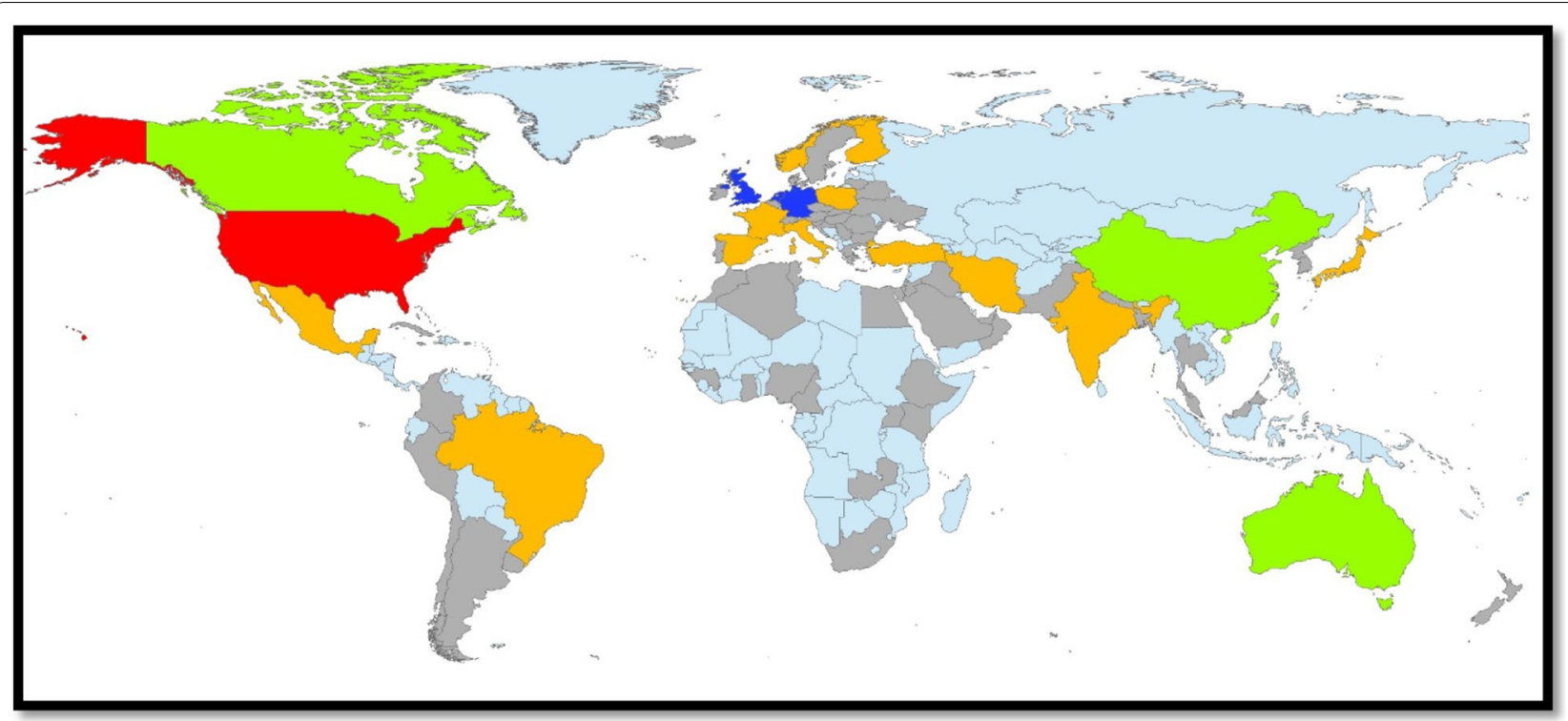

\section{Publications}

\begin{tabular}{|l|l}
\hline & $1-15$ \\
$\square$ & $16-41$ \\
$\square$ & $42-77$ \\
& $78-125$ \\
$126-674$
\end{tabular}

Fig. 3 Geographical distribution of publications in diabetes depression/suicide. No data were available from regions with light blue color

Table 5 List of top active institutions/organizations

\begin{tabular}{lllll}
\hline Institution/Organization & Frequency & $\%(\boldsymbol{N = 1 6 6 4 )}$ & $\boldsymbol{h}$-index of the publications & Country \\
\hline VA Medical Center & 75 & 4.5 & 31 & USA \\
University of Washington, Seattle & 73 & 4.4 & 38 & USA \\
Tilburg University & 51 & 3.1 & 22 & Netherlands \\
VU University Medical Center & 43 & 2.6 & 22 & Netherlands \\
Johns Hopkins University & 39 & 2.3 & 26 & USA \\
Washington University in St. Louis, School of & 37 & 2.2 & 15 & USA \\
Medicine & 34 & 2.0 & 8 & USA \\
University Michigan Ann Arbor & 31 & 1.9 & 16 & Canada \\
McGill University & 31 & 1.9 & 14 & USA \\
Harvard Medical School & 30 & 1.8 & USA \\
University of California, Los Angeles & & &
\end{tabular}

women, "African-Americans", Hispanics, and other related terms (Fig. 5).

\section{Discussion}

The purpose of this study was to assess and analyze global research output and research trends on diabetes depression/suicide. The current study was conducted based on the assumption that diabetes mellitus is a potential risk factor for depressive symptoms which could lead to suicidal ideation and death [39-41]. The current study showed that keywords such as screening and "primary healthcare" were most commonly encountered indicating that screening for depression primary healthcare centers is strongly advocated by researchers. 


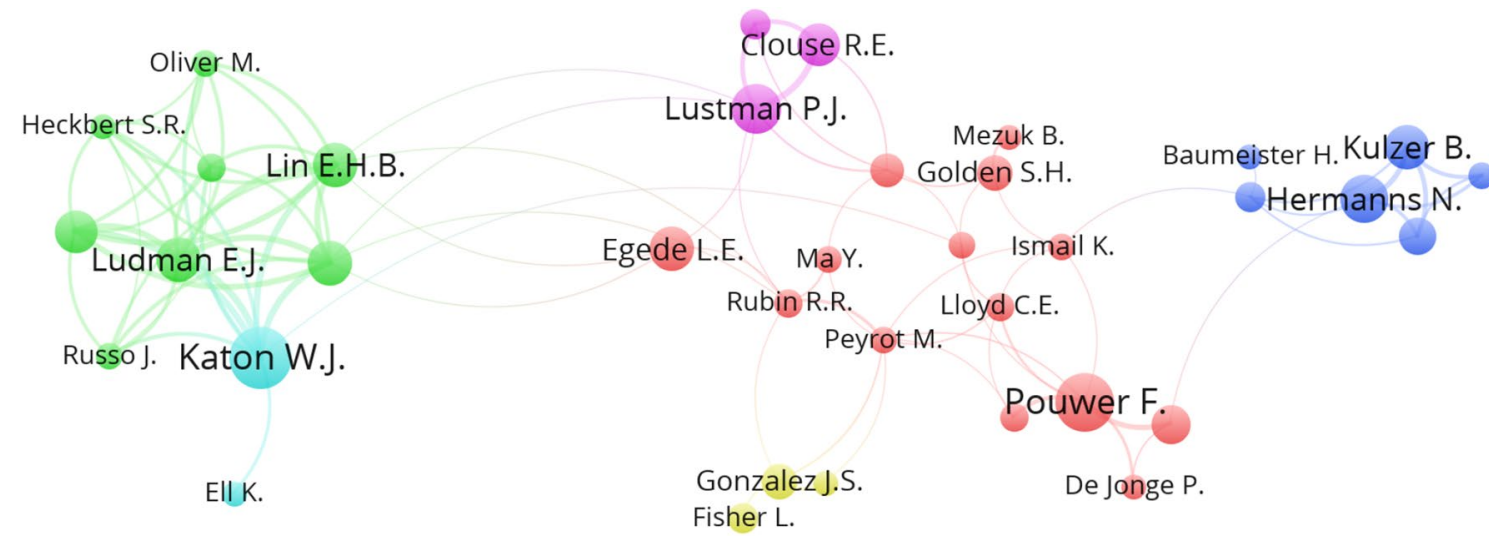

Fig. 4 Network visualization map of authors

Table 6 Top 20 cited articles in diabetes depression/suicide

\begin{tabular}{|c|c|c|c|c|}
\hline Title & References & Year & Source title & Cited by \\
\hline The prevalence of comorbid depression in adults with diabetes: a meta-analysis & {$[37]$} & 2001 & Diabetes Care & 2056 \\
\hline Depression and poor glycemic control: a meta-analytic review of the literature & {$[95]$} & 2000 & Diabetes Care & 1047 \\
\hline Association of depression and diabetes complications: a meta-analysis & {$[96]$} & 2001 & Psychosomatic Medicine & 987 \\
\hline $\begin{array}{l}\text { Depression and diabetes: impact of depressive symptoms on adherence, function, and } \\
\text { costs }\end{array}$ & [97] & 2000 & Archives of Internal Medicine & 935 \\
\hline Depression and type 2 diabetes over the lifespan: a meta-analysis & {$[40]$} & 2008 & Diabetes Care & 572 \\
\hline $\begin{array}{l}\text { The prevalence of co-morbid depression in adults with Type } 2 \text { diabetes: a systematic } \\
\text { review and meta-analysis }\end{array}$ & [39] & 2006 & Diabetic Medicine & 537 \\
\hline $\begin{array}{l}\text { Relationship of depression and diabetes self-care, medication adherence, and preven- } \\
\text { tive care }\end{array}$ & [98] & 2004 & Diabetes Care & 528 \\
\hline Prevalence of depression in adults with diabetes: an epidemiological evaluation & [99] & 1993 & Diabetes Care & 480 \\
\hline $\begin{array}{l}\text { The pathways study: a randomized trial of collaborative care in patients with diabetes } \\
\text { and depression }\end{array}$ & {$[100]$} & 2004 & Archives of General Psychiatry & 475 \\
\hline Depression as a risk factor for the onset of type 2 diabetes mellitus. a meta-analysis & [101] & 2006 & Diabetologia & 441 \\
\hline Examining a bidirectional association between depressive symptoms and diabetes & [102] & 2008 & $\begin{array}{l}\text { JAMA—Journal of the Ameri- } \\
\text { can Medical Association }\end{array}$ & 432 \\
\hline $\begin{array}{l}\text { Comorbid depression is associated with increased health care use and expenditures in } \\
\text { individuals with diabetes }\end{array}$ & [103] & 2002 & Diabetes Care & 426 \\
\hline Depression and risk for onset of type ii diabetes: a prospective population-based study & [104] & 1996 & Diabetes Care & 417 \\
\hline $\begin{array}{l}\text { Relationship of depression to diabetes types } 1 \text { and 2: epidemiology, biology, and } \\
\text { treatment }\end{array}$ & [105] & 2003 & Biological Psychiatry & 412 \\
\hline $\begin{array}{l}\text { Cognitive behavior therapy for depression in type } 2 \text { diabetes mellitus. A randomized, } \\
\text { controlled trial }\end{array}$ & [106] & 1998 & Annals of Internal Medicine & 395 \\
\hline The association of comorbid depression with mortality in patients with type 2 diabetes & [107] & 2005 & Diabetes Care & 371 \\
\hline Depression and diabetes treatment nonadherence: a meta-analysis & [108] & 2008 & Diabetes Care & 347 \\
\hline $\begin{array}{l}\text { Depression predicts increased incidence of adverse health outcomes in older Mexican } \\
\text { Americans with type } 2 \text { diabetes }\end{array}$ & [109] & 2003 & Diabetes Care & 338 \\
\hline Levels and risks of depression and anxiety symptomatology among diabetic adults & [110] & 1997 & Diabetes Care & 321 \\
\hline Diabetes, depression, and quality of life: a population study & [111] & 2004 & Diabetes Care & 314 \\
\hline
\end{tabular}

\section{Subject areas of the retrieved literature}

The current study showed that approximately $20 \%$ of publication in diabetes depression/suicide was within biochemistry/genetics/molecular biology subject area indicating that there was intensive research in the biological relationship between diabetes and depression. The hypothalamic-pituitary-adrenal (HPA) axis, cortisol, increased catecholamine, and proinflammatory cytokine 


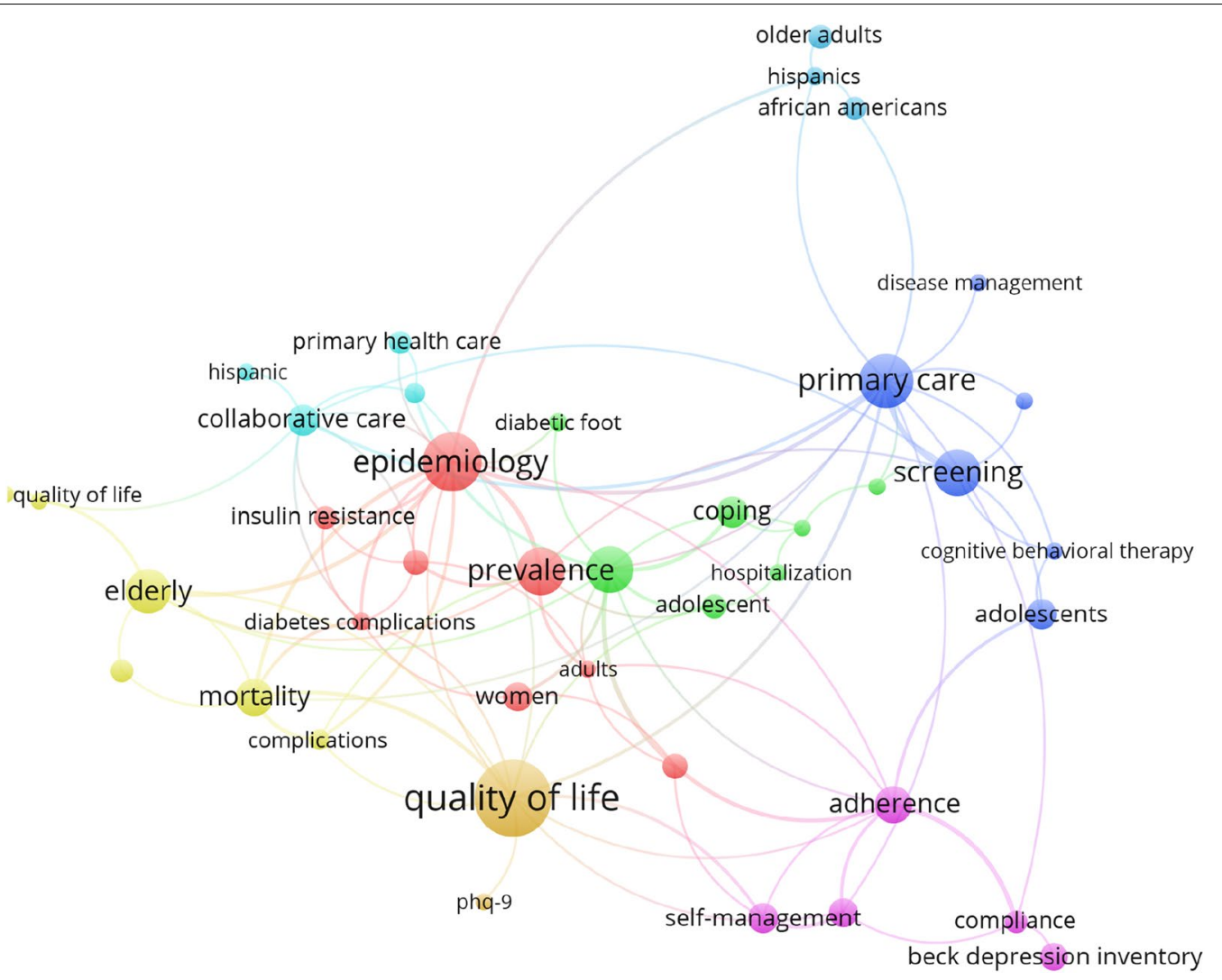

Fig. 5 Network visualization map of relevant author keywords

levels play a key role in development of insulin resistance $[12,42,43]$. The current study also showed that approximately $14 \%$ of retrieved documents were within the subject area of psychology. This was unsurprising given that coping behaviors and social support for diabetic patients might be different among different cultures and ethnicities [44-54].

\section{Growth of publications}

Research in diabetes depression/suicide started more than six decades ago, but the number of publications accelerated and showed a dramatic increase in the past decade. The growth of publication could be due to several factors. The overall increase in number of scholars, institutions, peer-reviewed journals, and global research output in the field of medicine positively affected the number of publications in diabetes depression/suicide. Second, certain findings regarding the scientific link between depression and poor glycemic control have triggered more research in this field. A third potential reason for the growth of publications was the debate about the bidirectional relationship between diabetes and depression and the role of depression as a potential risk factor for diabetes [13, 55-59]. The growth of publications is of great relevance to mental health practitioners and should argue in favor of routine depression screening in diabetic patients in primary healthcare facilities [60-68].

\section{Comparison with other diseases}

The current study showed that the growth of research on diabetes depression showed a steeper increase than that on cardiac or cancer-depression research. Actually, in the last 3 years of the study period, the number of publications in diabetes depression/suicide exceeded that of cardiac or cancer publications indicating a global interest in this field. Furthermore, $h$-index of publications related to diabetes depression was very close to that of cardiac and cancer suggesting that depression in all chronic diseases is a serious problem that is of interest to scholars.

\section{Geographical distribution of publications}

The current study showed that geographical distribution of publications was skewed toward developed countries, particularly USA, Canada, Australia, Germany, Netherlands, and UK. Other countries such as Brazil, India, and China were among top active countries. In 2000, India had the highest number of 
people with diabetes mellitus followed by China and the United States. It is predicted that by 2030 diabetes mellitus may afflict up to 79.4 million, 42.3 million, and 30.3 million individuals in India, China, and the USA, respectively, in 2030 [69-71]. Unfortunately, diabetes has been rising more rapidly in MLIC which necessitates more rigorous research in these countries to minimize diabetic complications and mortality [2]. Previously published studies also showed that contribution of LMIC to diabetes research did not match the health and economic burden of diabetes in these countries $[21,25,27,28,72-74]$. Not only diabetes research but also mental health research in LMIC was reported to be scarce [75-77]. The low research productivity from LMIC was also reflected in top 10 active institutions in diabetes depression/suicide research where no institution from LMIC showed up in the list.

\section{Highly cited documents}

An important aspect discussed in the top cited documents was the impact of depression on medication adherence and the potential risk of poor glycemic control. Studies showed that co-morbid diabetes and depression decreased the likelihood of adherence to lifestyle changes, specifically, diet, medication adherence, and physical activity resulting in elevated HbA1c and consequently poor self-care/self-management with increased risk of retinopathy, nephropathy, cardiac dysfunction, and mortality [78-84]. It had been found that depressive disorders decrease the desire to seek treatment making depression as an initial step of poor diabetes outcomes [85].

\section{Limitations}

The current study, like other bibliometric studies, has limitations that are inherent to bibliometric methodology and nature the database used [86-92]. Scopus database is not $100 \%$ comprehensive of literature, and therefore, some literature was missed particularly the ones published in un-indexed journals from developing countries. Second, the potential presence of false-negative results is a possibility due to the use of title search strategy. However, the title research strategy was used to minimize the false-positive results.

\section{Conclusion}

The current study showed an increasing interest of researchers in the psychiatric aspects of diabetes. This increasing interest is believed to promote the health of diabetic patients through initial screening of depression and through psychological and pharmacological treatment of the diseases. As a chronic disease with increasing global health burden, researchers need to get involved in all aspects that can alleviate the future complications of the disease to minimize health and economic burden of the disease. Future studies should focus on both epidemiological aspects in various cultures in developing countries and on the biological basis of depression in diabetic patients.

\section{Additional file}

Additional file 1: Appendix S1. Global research output in diabetes depression and suicide.

Abbreviation

DM: diabetes mellitus; WHO: World Health Organization.

Author contributions

WS: concept, data extraction, analysis and presentation, manuscript preparation, and manuscript submission and follow-up. The author read and approved the final manuscript.

\section{Acknowledgements}

None.

Competing interests

The author declares no competing interests.

Availability of data and materials

All data present in this article can be retrieved from Scopus using keywords listed in the methodology.

Consent for publication

Not applicable.

Ethics approval and consent to participate

Not applicable.

Funding

None.

\section{Publisher's Note}

Springer Nature remains neutral with regard to jurisdictional claims in published maps and institutional affiliations.

Received: 1 June 2018 Accepted: 16 October 2018

Published online: 23 October 2018

\footnotetext{
References

1. Armstrong C. Ada updates standards of medical care for patients with diabetes mellitus. Am Fam Physician. 2017;95(1):40-3.

2. World Health Organization: Global Report on Diabetes: World Health Organization; 2016.

3. Roglic G, Unwin N, Bennett PH, Mathers C, Tuomilehto J, Nag S, Connolly $\mathrm{V}$, King $\mathrm{H}$. The burden of mortality attributable to diabetes: realistic estimates for the year 2000. Diabetes Care. 2005;28(9):2130-5.

4. World Health Organization; Depression (Fact Sheet) http://www.who. int/mediacentre/factsheets/fs369/en/. Accessed 29 Jan 2018
} 
5. Bertolote JM, Fleischmann A. A global perspective in the epidemiology of suicide. Suicidologi. 2015;7(2):6-8.

6. World Health Organization; Suicide (Fact Sheet). http://www.who.int/ mediacentre/factsheets/fs398/en. Accessed 04 July 2017.

7. Cezaretto A, Siqueira-Catania A, de Barros CR, Salvador EP, Ferreira SRG. Benefits on quality of life concomitant to metabolic improvement in intervention program for prevention of diabetes mellitus. Qual Life Res. 2012;21(1):105-13.

8. Poulsen K, Pachana NA. Depression and anxiety in older and middleaged adults with diabetes. Aust Psychol. 2012:47(2):90-7.

9. Rubin RR, Peyrot M. Psychological issues and treatments for people with diabetes. J Clin Psychol. 2001;57(4):457-78.

10. Huang C-J, Lin C-H, Lee M-H, Chang K-P, Chiu H-C. Prevalence and incidence of diagnosed depression disorders in patients with diabetes: a National Population-Based Cohort Study. Gen Hosp Psychiatry. 2012;34(3):242-8.

11. Ciechanowski P. Diapression: an integrated model for understanding the experience of individuals with co-occurring diabetes and depression. Clin Diabetes. 2011;29(2):43-9.

12. Champaneri S, Wand GS, Malhotra SS, Casagrande SS, Golden SH Biological basis of depression in adults with diabetes. Curr Diab Rep. 2010;10(6):396-405

13. Pan A, Lucas M, Sun Q, Van Dam RM, Franco OH, Manson JE, Willett WC, Ascherio A, Hu FB. Bidirectional association between depression and type 2 diabetes mellitus in women. Arch Intern Med. 2010;170(21):1884-91.

14. Egede LE, Osborn CY. Role of motivation in the relationship between depression, self-care, and glycemic control in adults with type 2 diabetes. Diab Educator. 2010;36(2):276-83.

15. Fisher L, Glasgow RE, Strycker LA. The Relationship between diabetes distress and clinical depression with glycemic control among patients with type 2 diabetes. Diabetes Care. 2010;33(5):1034-6.

16. Egede LE, Ellis C. Diabetes and depression: global perspectives. Diab Res Clin Pract. 2010;87(3):302-12.

17. Pompili M, Lester D, Innamorati M, De Pisa E, Amore M, Ferrara C, Tatarelli R, Girardi P. Quality of life and suicide risk in patients with diabetes mellitus. Psychosomatics. 2009;50(1):16-23.

18. Pompili M, Forte A, Lester D, Erbuto D, Rovedi F, Innamorati M, Amore M, Girardi P. Suicide risk in type 1 diabetes mellitus: a systematic review. J Psychosom Res. 2014;76(5):352-60.

19. Thompson DF, Walker CK. A descriptive and historical review of bibliometrics with applications to medical sciences. Pharmacotherapy. 2015;35(6):551-9.

20. Dalton J, Garvey J, Samia LW. Evaluation of a Diabetes Disease Management Home Care Program. Home Health Care Manag Pract. 2006;18(4):272-85.

21. Sweileh WM, Zyoud SH, Al-Jabi SW, Sawalha AF. Bibliometric analysis of diabetes mellitus research output from middle eastern arab countries during the period (1996-2012). Scientometrics. 2014;101 (1):819-32.

22. Sweileh WM, Al-Jabi SW, Sawalha AF, AbuTaha AS, Zyoud SH. Bibliometric analysis of medicine-related publications on poverty (2005-2015). SpringerPlus. 2016;5(1):1888.

23. Sweileh WM, Al-Jabi SW, Sawalha AF, Zyoud SH. Bibliometric profile of the global scientific research on autism spectrum disorders. SpringerPlus. 2016:5(1):1480

24. Zyoud SH, Waring WS, Al-Jabi SW, Sweileh WM. Global cocaine intoxication research trends during 1975-2015: a bibliometric analysis of web of science publications. Subst Abuse. 2017;12(1):6.

25. Liu L, Jiao JH, Chen L. Bibliometric study of diabetic retinopathy during 2000-2010 by Isi. Int J Ophthalmol. 2011;4(4):333-6.

26. Peykari N, Djalalinia S, Kasaeian A, Naderimagham S, Hasannia T, Larijani B, Farzadfar F. Diabetes research in middle east countries; a scientometrics study from 1990 to 2012. J Res Med Sci. 2015;20(3):253-62.

27. Somogyi A, Schubert A. Correlation between National Bibliometric and Health Indicators: the Case of Diabetes. Scientometrics. 2005;62(2):285-92.

28. Yan B, Xiao H. Bibliometric analysis of diabetes literatures published in recent ten years. Acad J Sec Milit Med Univ. 2006;27(6):652-5.

29. Falagas ME, Pitsouni El, Malietzis GA, Pappas G. Comparison of pubmed scopus, web of science, and google scholar: strengths and weaknesses. FASEB J. 2008:22(2):338-42.
30. Werfalli M, Raubenheimer P, Engel M, Peer N, Kalula S, Kengne AP, Levitt NS. Effectiveness of community-based peer-led diabetes self-management programmes (Comp-Dsmp) for improving clinical outcomes and quality of life of adults with diabetes in primary care settings in low and middle-income countries (Lmic): a systematic review and meta-analysis. BMJ Open. 2015;5(7):e007635.

31. Teljeur C, Moran PS, Walshe S, Smith SM, Cianci F, Murphy L, Harrington P, Ryan M. Economic evaluation of chronic disease self-management for people with diabetes: a systematic review. Diabetic Med. 2016;34(8):1040-9.

32. Ahmad Sharoni SK, Minhat HS, Mohd Zulkefli NA, Baharom A. Health education programmes to improve foot self-care practices and foot problems among older people with diabetes: a systematic review. Int J Older People Nurs. 2016;11(3):214-39.

33. Lau Y, Htun TP, Wong SN, Tam WSW, Klainin-Yobas P. Efficacy of internet-based self-monitoring interventions on maternal and neonatal outcomes in perinatal diabetic women: a systematic review and metaanalysis. J Med Internet Res. 2016;18(8):e220.

34. Chrvala CA, Sherr D, Lipman RD. Diabetes self-management education for adults with type 2 diabetes mellitus: a systematic review of the effect on glycemic control. Patient Educ Couns. 2016;99(6):926-43.

35. Cui M, Wu X, Mao J, Wang X, Nie M. T2dm Self-management via smartphone applications: a systematic review and meta-analysis. PLOS ONE. 2016:11(11):e0166718.

36. van Eck NJ, Waltman L: Vosviewer Manual. In: Leiden: Univeristeit Leiden vol. 1; 2013

37. Anderson RJ, Freedland KE, Clouse RE, Lustman PJ. The prevalence of comorbid depression in adults with diabetes: a meta-analysis. Diabetes Care. 2001;24(6):1069-78.

38. Vogl A, Youngwirth SH. The Effects of a single dose of 2000 units of protamine zinc insulin taken by a diabetic patient with suicidal intent. N Engl J Med. 1949;241(16):606-9.

39. Ali S, Stone MA, Peters JL, Davies MJ, Khunti K. The prevalence of comorbid depression in adults with type 2 diabetes: a systematic review and meta-analysis. Diabet Med. 2006;23(11):1165-73.

40. Mezuk B, Eaton WW, Albrecht S, Golden SH. Depression and type 2 diabetes over the lifespan: a meta-analysis. Diabetes Care. 2008:31(12):2383-90

41. Nouwen A, Winkley K, Twisk J, Lloyd CE, Peyrot M, Ismail K, Pouwer F. Type 2 diabetes mellitus as a risk factor for the onset of depression: a systematic review and meta-analysis. Diabetologia. 2010;53(12):2480-6.

42. Jacobson AM, Samson JA, Weinger K, Ryan CM. Diabetes, the brain, and behavior: is there a biological mechanism underlying the association between diabetes and depression? Int Rev Neurobiol. 2002;51:455-79.

43. Musselman DL, Betan E, Larsen H, Phillips LS. Relationship of depression to diabetes types 1 and 2: epidemiology, biology, and treatment. Biol Psychiaty. 2003;54(3):317-29.

44. Black SA. Increased health burden associated with comorbid depression in older diabetic mexican Americans: results from the hispanic established population for the epidemiologic study of the elderly survey. Diabetes Care. 1999;22(1):56-64.

45. Chlebowy DO, Coty MB, Fu L, Hines-Martin V. Comorbid Diabetes and Depression in African Americans: Implications for the Health Care Provider. J Racial Ethnic Health Dispar. 2017;5:1-6.

46. De Groot M, Auslander W, Williams JH, Sherraden M, Haire-Joshu D. Depression and poverty among african american women at risk for type 2 diabetes. Ann Behav Med. 2003;25(3):172-81.

47. De Groot M, Lustman PJ. Depression among African-Americans with diabetes: a dearth of studies [2]. Diabetes Care. 2001;24(2):407-8.

48. Egede LE. Beliefs and attitudes of african americans with type 2 diabetes toward depression. Diab Educator. 2002;28(2):258-68.

49. Gary TL, Crum RM, Cooper-Patrick L, Ford D, Brancati FL. Depressive symptoms and metabolic control in African-Americans with Type 2 Diabetes. Diabetes Care. 2000;23(1):23-9.

50. Hernandez R, Ruggiero L, Prohaska TR, Chavez N, Boughton SW, Peacock N, Zhao W, Nouwen A. A Cross-Sectional Study of depressive symptoms and diabetes self-care in African Americans and Hispanics/Latinos with diabetes: the role of self-efficacy. Diab Educator. 2016;42(4):452-61. 
51. Husaini BA, Hull PC, Sherkat DE, Emerson JS, Overton MT, Craun C, Cain VA, Levine RS. Diabetes, depression, and healthcare utilization among African Americans in primary care. J Natl Med Assoc. 2004;96(4):476-84.

52. Kim MT, Kim KB, Ko J, Jang Y, Levine D, Lee HB. Role of depression in diabetes management in an ethnic minority population: a case of Korean Americans with type 2 diabetes. BMJ Open Diab Res Care. 2017:5(1):e000337.

53. Rehman SU, Shakaib A, Rashid S. Regarding depressive symptoms and metabolic control in African-Americans with type 2 diabetes [5] (multiple letters). Diabetes Care. 2000;23(10):1596-7.

54. Shah ZC, Huffman FG. Depression among hispanic women with type 2 diabetes. Ethn Dis. 2005;15(4):685-90.

55. Chen PC, Chan YT, Chen HF, Ko MC, Li CY. Population-based cohort analyses of the bidirectional relationship between type 2 diabetes and depression. Diabetes Care. 2013;36(2):376-82.

56. Golden SH, Lazo M, Carnethon M, Bertoni AG, Schreiner PJ, Diez Roux AV, Lee HB, Lyketsos C. Examining a bidirectional association between depressive symptoms and diabetes. JAMA. 2008:299(23):2751-9.

57. Jaser SS, Holl MG, Jefferson V, Grey M. Correlates of depressive symptoms in urban youth at risk for type 2 diabetes mellitus. J Sch Health. 2009;79(6):286-92.

58. Renn BN, Feliciano L, Segal DL. The bidirectional relationship of depression and diabetes: a systematic review. Clin Psychol Rev. 2011:31(8):1239-46.

59. Yu M, Zhang X, Lu F, Fang L. Depression and risk for diabetes: a metaanalysis. Can J Diab. 2015;39(4):266-72.

60. Burton C, Simpson C, Anderson N. Diagnosis and treatment of depression following routine screening in patients with coronary heart disease or diabetes: a database cohort study. Psychol Med. 2013;43(3):529-37.

61. Corathers SD, Kichler J, Jones NHY, Houchen A, Jolly M, Morwessel N, Crawford P, Dolan LM, Hood KK. Improving depression screening for adolescents with type 1 diabetes. Pediatrics. 2013;132(5):e1395-402.

62. Fleer J, Tovote KA, Keers JC, Links TP, Sanderman R, Coyne JC, Schroevers MJ. Screening for depression and diabetes-related distress in a diabetes outpatient clinic. Diabet Med. 2013;30(1):88-94.

63. Hermanns N, Caputo S, Dzida G, Khunti K, Meneghini LF, Snoek F. Screening, evaluation and management of depression in people with diabetes in primary care. Prim Care Diab. 2013;7(1):1-10.

64. Holt RG, van der Feltz-Cornelis CM. Key concepts in screening for depression in people with diabetes. J Affec Disorders. 2012;142:S72-9.

65. Monaghan M, Singh C, Streisand R, Cogen FR. Screening and identification of children and adolescents at risk for depression during a diabetes clinic visit. Diabetes Spectr. 2010;23(1):25-31.

66. Roy T, Lloyd CE, Pouwer F, Holt RIG, Sartorius N. Screening tools used for measuring depression among people with type 1 and type 2 diabetes: a systematic review. Diab Med. 2012;29(2):164-75.

67. Silverstein J, Cheng P, Ruedy KJ, Kollman C, Beck RW, Klingensmith GJ, Wood JR, Willi S, Bacha F, Lee J, et al. Depressive symptoms in youth with type 1 or type 2 diabetes: results of the pediatric diabetes consortium screening assessment of depression in diabetes study. Diabetes Care. 2015;38(12):2341-3.

68. Van Steenbergen-Weijenburg KM, De Vroege L, Ploeger RR, Brals JW, Vloedbeld MG, Veneman TF, Hakkaart-Van Roijen L, Rutten FF, Beekman AT, Van Der Feltz-Cornelis CM. Validation of the Phq-9 as a screening instrument for depression in diabetes patients in specialized outpatient clinics. BMC Health Serv Res. 2010;10:235.

69. Wild S, Roglic G, Green A, Sicree R, King H. Global prevalence of diabetes: estimates for the year 2000 and projections for 2030. Diabetes Care. 2004;27(5):1047-53

70. Whiting DR, Guariguata L, Weil C, Shaw J. Idf diabetes atlas: global estimates of the prevalence of diabetes for 2011 and 2030. Diabetes Res Clin Pract. 2011;94(3):311-21.

71. Kaveeshwar SA, Cornwall J. The current state of diabetes mellitus in India. Australas Med J. 2014;7(1):45.

72. De Lusignan S. Bibliometric analysis of primary care research, childhood obesity, the importance of understanding small area data and diabetes. Inform Prim Care. 2011;18(4):217-8.

73. Caglar C, Demir E, Kucukler FK, Durmus M. A bibliometric analysis of academic publication on diabetic retinopathy disease trends during 1980-2014: a global and medical view. Int J Ophthalmol. 2016;9(11):1663-8.
74. Nolan CK, Spiess KE, Meyr AJ. Where art thou diabetic foot disease literature? A bibliometric inquiry into publication patterns. J Foot Ankle Surg. 2015;54(3):295-7.

75. Razzouk D, Sharan P, Gallo C, Gureje O, Lamberte EE, de Jesus Mari J, Mazzotti G, Patel V, Swartz L, Olifson S. Scarcity and inequity of mental health research resources in low-and-middle income countries: a global survey. Health Policy. 2010;94(3):211-20.

76. Siriwardhana C, Sumathipala A, Siribaddana S, Samaraweera S, Abeysinghe N, Prince M, Hotopf M. Reducing the scarcity in mental health research from low and middle income countries: a success story from Sri Lanka. Int Rev Psychiatry. 2011;23(1):77-83.

77. Lund C. Poverty, inequality and mental health in low-and middleincome countries: time to expand the research and policy agendas. Epidemiol Psychiatr Sci. 2015;24(2):97.

78. Coelho CR, Zantut-Wittmann DE, Parisi MCR. A cross-sectional study of depression and self-care in patients with type 2 diabetes with and without foot ulcers. Ostomy Wound Manag. 2014;60(2):46-51.

79. Gaitonde P, Shaya FT. Relationship between depression, self-care behaviors, and treatment success among older medicare beneficiaries with type 2 diabetes. J Pharm Health Serv Res. 2016;7(4):241-5.

80. Kokoszka A. Treatment adherence in patients with type 2 diabetes mellitus correlates with different coping styles, low perception of self-influence on disease, and depressive symptoms. Patient Preference Adherence. 2017;11:587-95.

81. Matsunaga S, Tanaka S, Fujihara K, Horikawa C, limuro S, Kitaoka M, Sato A, Nakamura J, Haneda M, Shimano H, et al. Association between all-cause mortality and severity of depressive symptoms in patients with type 2 diabetes: analysis from the japan diabetes complications study (jdcs). J Psychosom Res. 2017;99:34-9.

82. Rees G, Xie J, Fenwick EK, Sturrock BA, Finger R, Rogers SL, Lim L, LamoureuX EL. Association between diabetes-related eye complications and symptoms of anxiety and depression. JAMA Ophthalmol. 2016;134(9):1007-14.

83. Shin N, Hill-Briggs F, Langan S, Payne JL, Lyketsos C, Golden SH. The association of minor and major depression with health problemsolving and diabetes self-care activities in a clinic-based population of adults with type 2 diabetes mellitus. J Diabetes Complications. 2017:31(5):880-5

84. Sumlin LL, Garcia TJ, Brown SA, Winter MA, García AA, Brown A, Cuevas HE. Depression and adherence to lifestyle changes in type 2 diabetes: a systematic review. Diab Educator. 2014;40(6):731-44.

85. Egede LE. Effect of depression on self-management behaviors and health outcomes in adults with type 2 diabetes. Curr Diab Rev. 2005;1(3):235-43.

86. Sweileh WM, Wickramage K, Pottie K, Hui C, Roberts B, Sawalha $\mathrm{AF}$, Zyoud $\mathrm{SH}$. Bibliometric analysis of global migration health research in peer-reviewed literature (2000-2016). BMC Public Health. 2018;18(1):777

87. Sweileh WM. Bibliometric analysis of literature in aids-related stigma and discrimination. Transl Behav Med. 2018. https://doi.org/10.1093/ tbm/iby072.

88. Sweileh WM. Bibliometric analysis of medicine-related publications on refugees, asylum-seekers, and internally displaced people: 2000-2015. BMC Int Health Hum Rights. 2017;17(1):7.

89. Sweileh WM. Bibliometric analysis of peer-reviewed literature in transgender health (1900-2017). BMC Int Health Hum Rights. 2018;18(1):16.

90. Sweileh WM. Global output of research on epidermal parasitic skin diseases from 1967 to 2017. Infect Dis Poverty. 2018;7(1):74.

91. Sweileh WM. Global research output in the health of international arab migrants (1988-2017). BMC Public Health. 2018;18(1):755.

92. Sweileh WM. Global research trends of World Health Organization's top eight emerging pathogens. Global Health. 2017;13(1):9.

93. World Health Organization (WHO). Diabetes Country Profile. http:// www.who.int/diabetes/country-profiles/en/. Accessed 29 Jan 2018.

94. World Health Rankings: Diabets mellitus death rate per 100,000 age standardized. 2016.

95. Lustman PJ, Anderson RJ, Freedland KE, de Groot M, Carney RM, Clouse RE. Depression and poor glycemic control: a meta-analytic review of the literature. Diabetes Care. 2000;23(7):934-42. 
96. de Groot M, Anderson R, Freedland KE, Clouse RE, Lustman PJ. Association of depression and diabetes complications: a meta-analysis. Psychosom Med. 2001;63(4):619-30.

97. Ciechanowski PS, Katon WJ, Russo JE. Depression and diabetes: impact of depressive symptoms on adherence, function, and costs. Arch Intern Med. 2000;160(21):3278-85.

98. Lin EH, Katon W, Von Korff M, Rutter C, Simon GE, Oliver M, Ciechanowski P, Ludman EJ, Bush T, Young B. Relationship of depression and diabetes self-care, medication adherence, and preventive care. Diabetes Care. 2004;27(9):2154-60

99. Gavard JA, Lustman PJ, Clouse RE. Prevalence of depression in adults with diabetes: an epidemiological evaluation. Diabetes Care. 1993:16(8):1167-78.

100. Katon WJ, Von Korff M, Lin EH, Simon G, Ludman E, Russo J, Ciechanowski $P$, Walker E, Bush T. The pathways study: a randomized trial of collaborative care in patients with diabetes and depression. Arch Gen Psychiatry. 2004;61(10):1042-9.

101. Knol MJ, Twisk JW, Beekman AT, Heine RJ, Snoek FJ, Pouwer F. Depression as a risk factor for the onset of type 2 diabetes mellitus. A metaanalysis. Diabetologia. 2006:49(5):837-45.

102. Golden SH, Lazo M, Carnethon M, Bertoni AG, Schreiner PJ, Diez Roux $A V$, Lee HB, Lyketsos C. Examining a bidirectional association between depressive symptoms and diabetes. JAMA. 2008;299(23):2751-9.

103. Egede LE, Zheng D, Simpson K. Comorbid depression is associated with increased health care use and expenditures in individuals with diabetes. Diabetes Care. 2002;25(3):464-70.
104 Eaton WW Armenian H, Gallo J, Pratt L, Ford DE. Depression and risk for onset of type ii diabetes. A prospective population-based study. Diabetes Care. 1996:19(10):1097-102.

105. Musselman DL, Betan E, Larsen H, Phillips LS. Relationship of depression to diabetes types 1 and 2: epidemiology, biology, and treatment. Biol Psychiatry. 2003;54(3):317-29.

106. Lustman PJ, Griffith LS, Freedland KE, Kissel SS, Clouse RE. Cognitive behavior therapy for depression in type 2 diabetes mellitus. A randomized, controlled trial. Ann Intern Med. 1998;129(8):613-21.

107. Katon WJ, Rutter C, Simon G, Lin EH, Ludman E, Ciechanowski P, Kinder L, Young B, Von Korff M. The association of comorbid depression with mortality in patients with type 2 diabetes. Diabetes Care. 2005;28(11):2668-72.

108. Gonzalez JS, Peyrot M, McCarl LA, Collins EM, Serpa L, Mimiaga MJ, Safren SA. Depression and diabetes treatment nonadherence: a metaanalysis. Diabetes Care. 2008;31(12):2398-403.

109. Black SA, Markides KS, Ray LA. Depression predicts increased incidence of adverse health outcomes in older Mexican Americans with type 2 diabetes. Diabetes Care. 2003;26(10):2822-8.

110. Peyrot M, Rubin RR. Levels and Risks of Depression and Anxiety Symptomatology among Diabetic Adults. Diabetes Care. 1997;20(4):585-90.

111. Goldney RD, Phillips PJ, Fisher LJ, Wilson DH. Diabetes, depression, and quality of life: a population study. Diabetes Care. 2004;27(5):1066-70.
Ready to submit your research? Choose BMC and benefit from:

- fast, convenient online submission

- thorough peer review by experienced researchers in your field

- rapid publication on acceptance

- support for research data, including large and complex data types

- gold Open Access which fosters wider collaboration and increased citations

- maximum visibility for your research: over 100M website views per year

At BMC, research is always in progress.

Learn more biomedcentral.com/submissions 